\title{
Incidental diagnosis of a gastric mass on chest radiographs
}

\section{W F C van Gelderen FCRad(D) SA}

Department of Radiology, Masterton Hospital, Masterton, New Zealand

\section{Abstract}

Careful inspection of the infradiaphragmatic area on chest radiographs may lead to diagnosis of different conditions such as gastric fundal masses, sub-diaphragmatic free air, subphrenic abscess, bowel obstruction, etc. Case histories are presented for 4 patients in whom the diagnosis of a gastric tumour was made on chest X-ray.

The importance of including the infradiaphragmatic area as a review area of the chest X-ray is emphasised.

\section{Introduction}

Traditional review areas on chest radiographs (important areas that should be reviewed after a systematic examination of the radiographs) include the lung apices, the hilar regions, the retrocardiac area and the costophrenic angles. ${ }^{1}$ The infradiaphragmatic area is not a classical review area, but can easily be added to the last-named review area as many important entities may be identified.
Conditions include subdiaphragmatic free air, bowel obstruction, hepatic or splenic calcification, signs of previous surgery, subphrenic abscess and abnormality of the gastric air bubble.

Over a 20-year period 4 cases of a mass in the cardia of the stomach were incidentally detected on chest radiographs by the author.

\section{Case reports}

\section{Case 1}

A 59-year-old man scheduled for eye surgery was referred for preoperative chest radiographs (Fig. 1a). These revealed signs of chronic obstructive airways disease, a segmental atelectasis in the left lower lobe and an oblong air loculus projecting beyond the left tracheal border. (The latter was due to a localised traction diverticulum, well demonstrated on subsequent barium swallow, and secondary to previous tuberculosis in the left upper lobe).

A $5.5 \times 4.0 \mathrm{~cm}$ rounded mass was identified in the gastric cardia, convex to lateral and extending into the gas shadow of the gastric fundus. The mass was noted to be well-defined, homogeneous, and apparently entirely intragastric on barium examination (Fig. 1b). The radiological diagnosis of a leiomyoma was confirmed by biopsy.

\section{Case 2}

A 61-year-old woman, a known
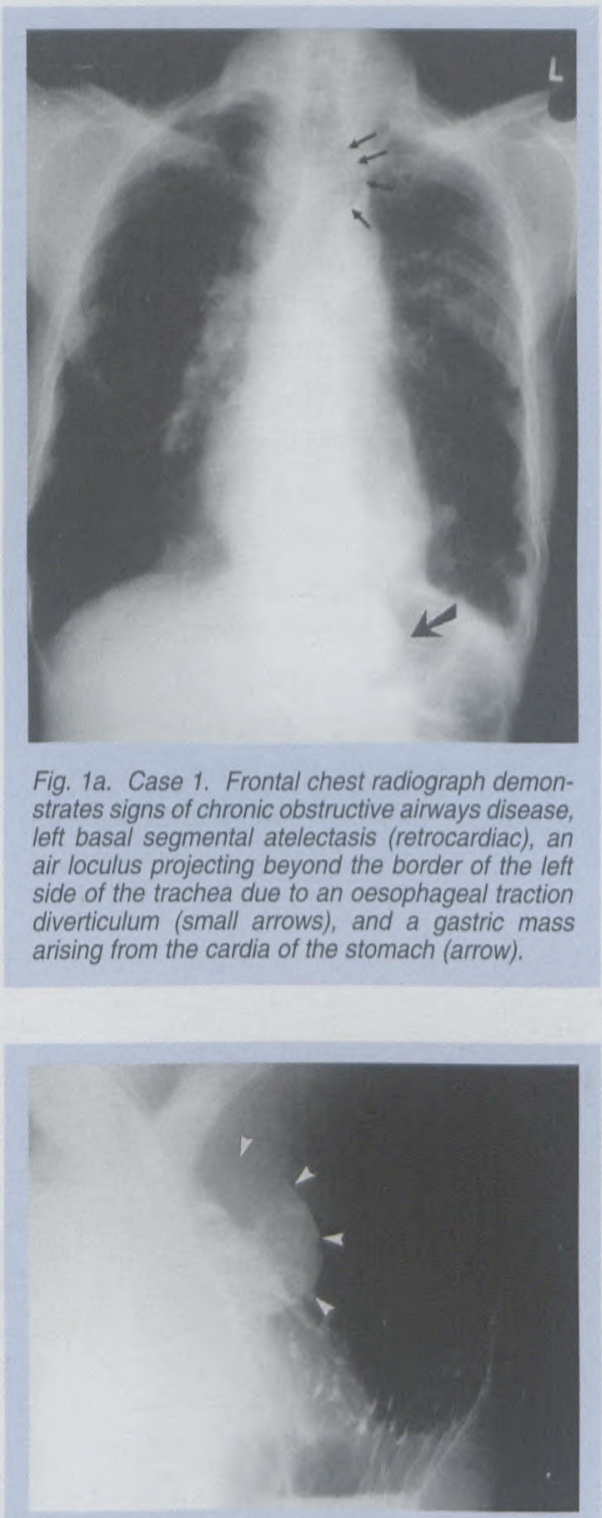

Fig. 1b. Case 1. Barium meal confirms mass (leiomyoma) (arrowheads) arising from the cardia of the stomach.

asthmatic, presented with acute dyspnoea and cough and a clinical diagnosis of pneumonia was favoured. A frontal chest radiograph revealed a large right-sided pneumothorax, which was treated with an intercostal drainage tube. Once the right lung had re-expanded underlying tuberculous infiltration was identified (Fig. 2) and active tuberculosis was confirmed clinically. The tuberculosis was treated effectively, and chest films taken 6 


\section{ORIGINAL ARTICLE}
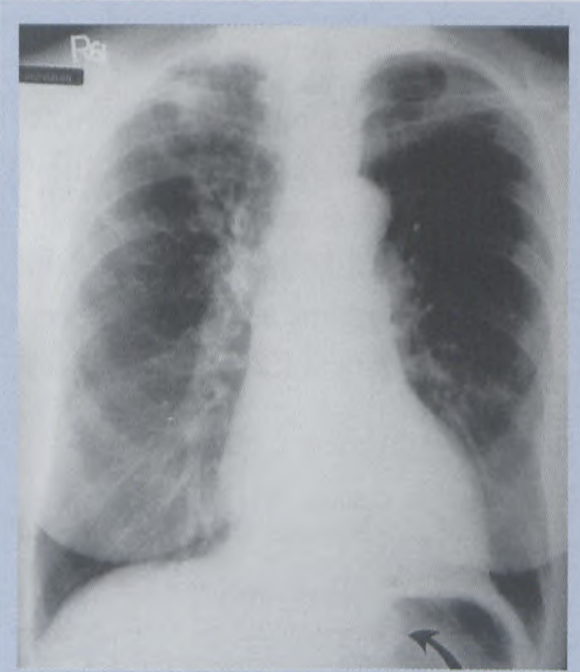

Fig. 2. Case 2. Frontal chest $X$-ray shows signs of active tuberculous disease in the right upper lobe and a small rounded mass within the cardia of the stomach (arrow) (unconfirmed leiomyoma).

months later only demonstrated some residual fibrotic scarring.

A $2.7 \times 2.7 \mathrm{~cm}$ mass, quite obvious as it was well outlined by air, was noted on all the chest radiographs within the gastric cardia.

Reviewing the X-rays, a barium study performed 4 years previously was discovered in another X-ray packet and demonstrated the mass to be the same size as the mass on chest radiographs 4 years later. The surgeon opted for a conservative approach, and the radiological diagnosis of a leiomyoma was not confirmed.

\section{Case 3}

A 55-year-old woman with known chronic obstructive airways disease was referred for chest radiographs. In addition to the airways disease, a large rounded mass convex to anterior, with a semilunar gas shadow within the stomach in front of it, was demonstrated on the left lateral film (Fig. 3a). The frontal film did not reveal the mass and little gas was seen in the stomach. A barium meal was recommended and 4 days later the patient

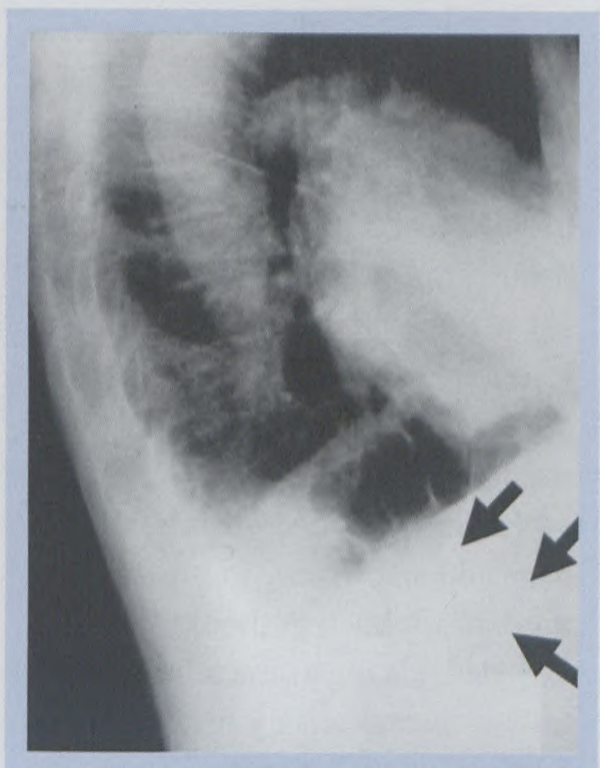

Fig. 3a. Case 3. Lateral chest radiography demonstrates an apparent mass in the stomach protruding convex to anterior (arrows) with a semilunar gastric air shadow anteriorly.

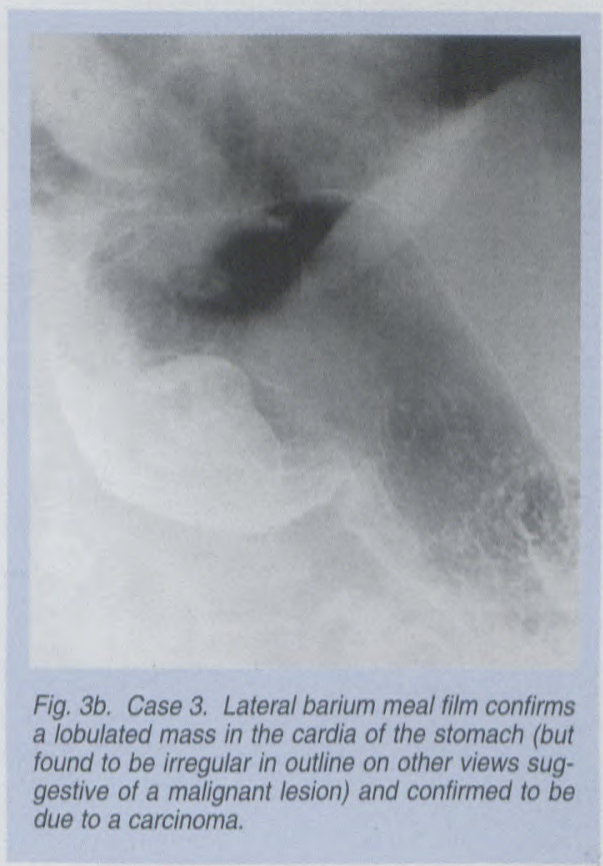

presented with the request form making mention of peptic ulcer symptoms, profound anaemia and occult blood in the stool. The barium meal (Fig. 3b) confirmed the $6.0 \times 5.5 \mathrm{~cm}$ mass, which was lobulated and thought to be due to a leiomyoma or a carcinoma. Gastroscopy demon- strated a polypoid mass with a malignant appearance, confirmed on histology.

\section{Case 4}

A 72-year-old woman was referred for a preoperative chest X-ray which demonstrated an apparently incidental $3.0 \times 2.7 \mathrm{~cm}$ mass in the gastric cardia (Fig. 4a). Previous films were obtained at a later stage and it became evident that a gastric carcinoma had already been diagnosed by endoscopy and abdominal computed tomography (CT) (Fig. 4b). The patient had presented with loss of weight,

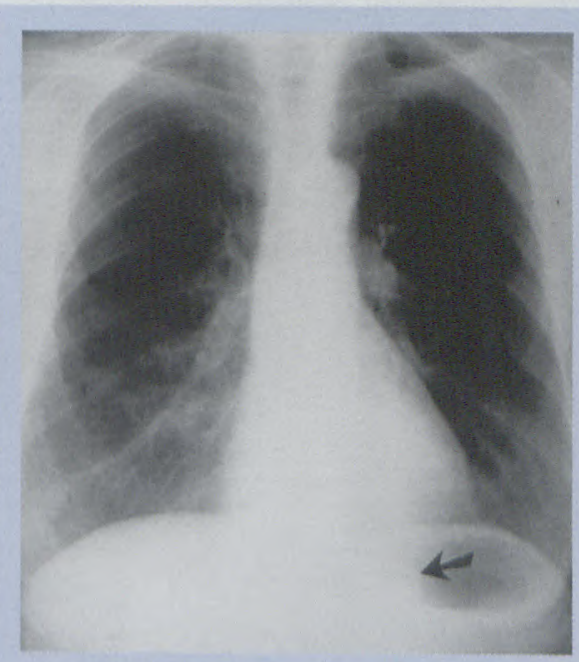

Fig. 4a. Case 4. Frontal chest radiography demonstrates a small lobulated mass (arrow) situated in the cardia of the stomach protruding into the gastric air bubble convex to lateral.

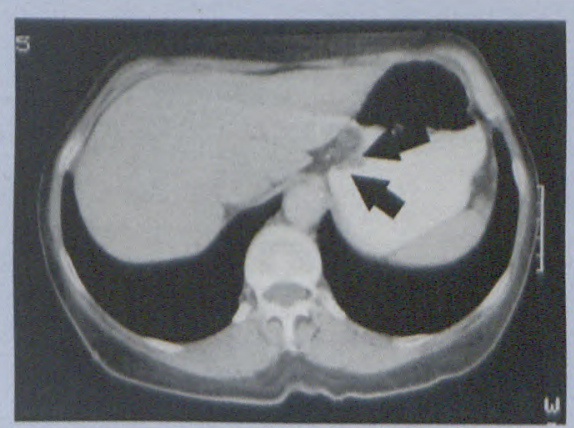

Fig. 4b. Case 4. Axial CT section shows a small mass in the cardia of the stomach (arrows) without extragastric involvement or lymphadenopathy and due to a well-differentiated adenocarcinoma. 


\section{ORIGINAL ARTICLE}

anaemia and a central abdominal mass. CT had demonstrated the mass in the gastric cardia without extragastric extension or lymphadenopathy. A well-differentiated adenocarcinoma was surgically resected.

\section{Discussion}

Gas was noted to be present in the stomach in 500 of 700 normal chest radiographs. ${ }^{2}$ Absence of gas in the stomach may occur associated with oesophageal disease, e.g. carcinoma or achalasia. The gas shadow of the gastric fundus may be indented by a normal left lobe of the liver on its medial aspect or the spleen on its lateral aspect. $^{3}$ An adjacent mass, such as a subphrenic abscess, may also indent the stomach, but other signs such as a left pleural effusion would usually be associated with a subphrenic abscess.
Apart from an extrinsic impression, an intraluminal mass such as a food bolus or bezoar should be considered. Previous surgery for hiatus hernia (fundoplication) can also deform the gastric fundus and simulate a mass. ${ }^{4}$ Gastric varices and an inverted hiatus hernia can likewise cause a 'mass' in the cardia of the stomach.

Having excluded an intraluminal mass and an extrinsic impression, the third possibility that should always be excluded relating to any tubular structure, is disease arising from the wall. In the above case studies, a leiomyoma (often ovoid or rounded with a welldefined outline) or a carcinoma (often less rounded, often lobulated and/or ill-defined polypoid) was responsible in each case.

In the cases diagnosed incidentally, the mass within the stomach was rounded, of soft tissue density and clearly outlined by air for at least half of its circumference. In all these instances, however, the mass could have been easily overlooked if the infradiaphragmatic area had not been included as one of the review areas.

\section{References}

1. Pierce JW, Graigner RG. The normal chest: techniques. In: Sutton D, ed. A Textbook of Radiology and Imaging. 3rd ed. Edinburgh: Churchill Livingstone, 1980: 260.

2. Felson B. A review of over 30000 normal chest roentgenograms. In: Felson B, ed. Chest Roentgenology. Philadelphia: WB Saunders, 1973: 498-499.

3. Chapman AH. The stomach and duodenum. In: Sutton D, ed. A Textbook of Radiology and Imaging. 6th ed. Edinburgh: Churchill Livingstone, 1998: 831-832.

4. Berk RN. The postoperative stomach. In: Teplick JG, Haskin ME, eds. Surgical Radiology. Philadelphia: WB Saunders, 1981: 490. 